\title{
Protecting the environment as an international process: Black Sea Economic Cooperation (BSEC)
}

\author{
Çora Hakan ${ }^{1}$, Mikail Elnur Hasan ${ }^{2, *}$, and Gül Sevda ${ }^{2}$ \\ ${ }^{1}$ Istanbul Okan University, Istanbul, Turkey \\ ${ }^{2}$ Kafkas University, Kars, Turkey
}

\begin{abstract}
At In this paper, it was attempted to examine and analyze the environmental and sociological impact of Black Sea Economic Cooperation Organization (BSEC) that was established in June 1992 in Istanbul. Members of the organization are Albania, Azerbaijan, Bulgaria, Armenia, Georgia, Moldova, Romania, Russia, Turkey, Ukraine and Greece. The researchers and scholars should keep in mind that The Commission on the Protection of the Black Sea Against Pollution (the Black Sea Commission or BSC), through its Permanent Secretariat, is the intergovernmental association founded in execution of the Convention on the Protection of the Black Sea Against Pollution (Bucharest Convention), its Protocols and the Strategic Action Plan for the Environmental Protection and Rehabilitation of the Black Sea. Therefore, through BSEC, in the Summit Declaration signed with the participation of the Heads of State and Government of 11 member countries, the Black Sea region is envisaged to be a zone of peace, stability, and welfare. The mechanism chosen to achieve this goal is environmental, economic and social cooperation.
\end{abstract}

\section{Introduction}

It is known that in the years following the end of the cold war and the collapse of the Berlin Wall, both the Balkan countries and the Caucasian countries entered a process of rapid and radical change. It is not necessary to go back to remember what kind of conflict and tension the Balkans and the Caucasus area. Bosnia-Herzegovina and Kosovo crises and Armenia's occupation of Azerbaijani territories maintain their vitality in the minds of the international public. Balkan and Caucasian countries, which saw each other as opposites due to historical reasons and some of them took their places in hostile camps in bipolar world order; the first time came together under the leadership of Turkey have taken an important step towards regional economic integration [1].

The Black Sea Economic Cooperation Organization gathers the important producer and consumer countries of the world, especially in the field of energy, under its roof. The economic development levels of the members of the organization are different. The

\footnotetext{
* Correspondent author: emikail@turansam.org
} 
member countries that were governed by the central economy before 1989 are going through an economic transformation process and are trying to adapt rapidly to the conditions of the free market economy. The members of the BSEC, especially in the Balkans, believe that the Organization can accelerate the integration with the European Union by increasing the cooperation between the member countries [2].

The aims of the Southeast Europe Cooperation Initiative (SECI) and the South East Europe Stability Pact (IP), which are aimed at the reconstruction and revival of the Balkans, and the works carried out in this context are towards the same goal as BSEC. In other words, the aims and objectives of the BSEC are similar to the aims and targets of SECI and IP, valid in the region between the Balkans and the Caucasus. In addition, it should be taken into consideration that the BSEC is the product of intra-regional dynamics, unlike these initiatives [1].

While the BSEC foresees cooperation that will contribute to the economic development of the countries in the region, it also mediates the gathering of businessmen. BSEC is an organization that envisages cooperation in different sectors of the economy. The BSEC Business Council was established for this cooperation [2].

Trade is a leading element of the BSEC process. Increasing interregional trade and removing barriers to trade are among the priority targets of BSEC. As a matter of fact, the establishment document of the BSEC stipulates the establishment of a Free Trade Zone in the region. In addition to trade, foreign direct investments and technology transfer are also included in the action area of BSEC as factors that accelerate economic development in the member countries [3].

Border and coastal trade, liberalization of trade, encouragement of SMEs, facilitating the cross-border movement of goods and persons, relaxation of visa rules in business travels are still on the BSEC agenda. On the other hand, one of the most important fields of cooperation of the BSEC Organization is communication. Communication and transportation networks constitute the strategic elements of economic integration in both national and regional areas [4].

BSEC has implemented three projects in the field of communication. The first one of these projects, namely ITUR, has connected Turkey, Ukraine and Russia with a $3200 \mathrm{~km}$ of submarine fiber optic cable system. The second project, KAFOS, was held with the participation of Turkey, Bulgaria, Romania and Moldova. Thanks to the KAFOS system, a direct connection can be established between Istanbul and Varna and Chisinau. The third project is the project known as the Trans Balkan Line (TBL). With this project, Italy, Macedonia, Albania, Bulgaria and Turkey are linked together [3].

\section{Transport and communication sectors constitute the lifeblood of the BSEC process}

In a document prepared by the member countries' experts, they determined the national infrastructures and the most preferred connections of the BSEC countries until 2005 by mapping the rail and road transport, ports, and sea routes in the region. Thanks to this map, the most cost-effective transport connections at the regional level have been determined, and integration to the European transport system will be possible with future connections to the existing infrastructure. There are four important transportation projects that BSEC has focused on. These are a) in North-South directions, between Baltic Sea Central Russia, Azov and Black Sea, the Pan-European 9th corridor; b) in East-West directions, between Adriatic Sea, Black Sea and Central Asia, the Pan-European 8th corridor ; c) between Danube and Don Volga rivers, the Pan-European 7th corridor; and d) Black Sea Pan European Transport Area (Black Sea PETrA) [1]. 
When it comes to the transportation issue in terms of the seas of the region, it is seen that maritime transportation can be one of the important cooperation areas of BSEC. On the other hand, the increasing maritime traffic in the Bosphorus and the Dardanelles straits puts the issue of sea transportation in a position that needs to be focused on sensitively, especially in terms of the environment [4].

It will be useful to remember that the geography of the Black Sea Economic Cooperation Organization is the region with the largest oil deposits in the world, following the Gulf, to deliver the place of energy issue in cooperation. In addition to 200 billion barrels of oil deposits in the Caspian basin, 27 percent of the world's natural gas reserves are situated in this region. The geostrategic importance of the BSEC is due to the fact that it has a significant amount of oil and natural gas deposits in its geographic area and that energy transport routes to the Western world pass over its territory [2].

The strategic importance of oil and natural gas, which constitute the basic energy resources, at the global level is an undeniable fact. However, these resources can also play an important role in establishing regional peace, stability, and comfort. The members of the BSEC include both countries with rich oil and natural gas deposits and countries without these natural resources. By publishing a report titled "Energy Situation in the Black Sea Region", the BSEC countries also reviewed the issues related to the intra-regional market for oil and natural gas, the availability of energy deposits, the extraction, transportation, distribution and marketing of energy [5].

The efficient marketing of the energy resources to be obtained from the natural gas and oil deposits in the BSEC region to the consumer countries in the Western world through pipelines without harming the environment will help to increase the prosperity as well as the establishment of lasting peace in the region. Thus, the relations between the BSEC countries will be built on more solid foundations [3].

The BSEC countries also carried out a study on the interconnection of electricity networks in the member countries. Member countries signed the Cooperation Memorandum in Yerevan on April 15, 1998, which envisages cooperation in the Electric Energy Industry.

The vast and fertile lands covered by the BSEC Region provide the necessary potential for the member states to engage in intensive cooperation in the field of agriculture. Studies in this area focus on plant breeding, soil improvement, animal breeding and veterinary science, aquaculture and environment [4].

In agriculture, it is considered that the agriculture-based industry, food processing industry, and packaging industry can be attractive cooperation areas in the future.

\section{The subject of environmental protection is another field of study that the Black Sea Economic Cooperation Organization attaches importance to}

In this framework, countries riparian with the Black Sea signed the Convention for the Protection of the Black Sea Against Pollution (Bucharest Convention) on April 22, 1992 in Bucharest. Subsequently six BSEC member countries (Bulgaria, Georgia, Romania, Russia, Turkey, and Ukraine) signed the Black Sea Ecological Program. The Black Sea Ecological Program envisages the realization of a Strategic Action Plan for the protection and rehabilitation of the Black Sea. The Strategic Action Plan envisages cooperation in three different areas. These are a) reduction of pollution, b) management of vital resources (fisheries and maintenance of biodiversity of the human environment) and c) sustainable social development of the coastal zone [6].

On the other hand, the States Parties to the Bucharest Convention have established the Commission for the Protection of the Black Sea Against Pollution, which will provide 
Secretariat services to the States Parties in accordance with the 17th article of the Convention, and the aforementioned Commission entered into service in Istanbul on 15 October 2000 [3].

BSEC Statistical Data Exchange and Economic Information Coordination Center were established within the State Statistics Institute in Ankara due to the lack of compatible statistical data that could be useful to the Organization in transition economy countries, which are members of the Black Sea Economic Cooperation Organization. The center works as a coordinating body and collects statistical and economic information from member countries by acting as a clerk [7].

Being aware of the importance of banking and financial affairs in free-market economies, member countries signed the Black Sea Trade and Development Bank's Founding Agreement in Tbilisi on January 30, 1994. The Bank aims to support private sector entrepreneurship and is headquartered in Thessaloniki. It is envisaged that the Bank, established in 1998, will constitute the financial basis of the BSEC and help the realization of these by providing loans to the projects in the region. The BSEC Bank of Trade and Development also has functions such as stimulating intra-regional trade, helping to carry out various transfers and transactions in the business field, channeling financial resources within the BSEC, financing feasible joint projects, promoting co-financing in the international arena, and providing investment flow to the region [1].

One of the areas of cooperation among the member countries of the Black Sea Economic Cooperation Organization is tourism. The private sectors of the member countries should play an active role in the field of tourism. In the field of tourism, the superstructure should be raised to a level that can meet today's needs as well as strengthening the infrastructure. Turkey has undertaken the coordination among the member countries in the field of tourism for the year 2000. In this context, Turkish Ministry of Tourism has organized courses and training programs for member country participants [3].

The International Black Sea Studies Center was established in Athens in order to develop the objectives of the Black Sea Economic Cooperation Organization and to identify new opportunities and cooperation areas. The center functions as a research institution in a sense. The Center has recently prepared a draft document titled "Economic Agenda for the Future" in cooperation with the BSEC Permanent Secretariat. In the document, the issues that BSEC should realize in almost all sectors of the economy in order to be successful in the 21 st century are outlined. If the document is accepted in the next meeting of the Council of Ministers of Foreign Affairs, which is the decision-making body of the BSEC, and if it is implemented in the future, it will increase the effectiveness of the Organization [8].

Another establishment of the Black Sea Economic Cooperation Organization is the BSEC Parliamentary Assembly (PABSEC). The PABSEC was established on 25 February 1993. It has an International Secretariat and a General Secretary. International Secretariat is located in Istanbul. The PABSEC, which coordinates the parliaments of the member countries in order to provide the necessary support in the implementation of the decisions taken by the BSEC Council of Ministers of Foreign Affairs, accelerates the development of cooperation between the member countries. The PABSEC adds the BSEC a pluralistic dimension [2].

The headquarters of the BSEC Business Council, another affiliate of the Black Sea Economic Cooperation Organization established in 1992, is located in Istanbul, and its activities are carried out by a Board of Directors consisting of businessmen from member countries. It is acknowledged that the private sector has an important role to play in the development strategies of the BSEC member countries based on market economy. The BSEC Business Council not only brings together the business circles of the member 
countries, but also contributes to the search for cooperation opportunities for businessmen between the Black Sea region and, for example, the MERCOSUR region [3].

The Black Sea Economic Cooperation Organization is a regional economic cooperation organization that has a future in Eurasia and has undertaken important tasks. On the other hand, the fact that many countries have applied to become a member of the BSEC or gain observer status shows that the Organization has started to gain ground in the international community. Moreover, establishing the BSEC relations with the United Nations and other international organizations and strengthening these ties will undoubtedly contribute to the establishment of closer relations of the organization with the international community [9].

With the entry into force of the host country agreement in August 2000, it was enabled for the member countries to open a Permanent Representation in the presence of the BSEC and to appoint a Permanent Representative. It is believed that the activation of these Permanent Representatives will bring dynamism to the Organization [2].

The BSEC Presidency rotates every six months between member states. The current presidency of the Russian Federation will be transferred to Turkey from April 27, 2001. The TROIKA consultations, aimed at bringing together the previous, current and next BSEC presidents to ensure continuous exchange and flow of information about the organization, took place in Moscow on 6 April 2001 between Romania, Russia and Turkey [10]. On the other hand, prior to the TROIKA consultations, a document titled "Economic Agenda 2000" was prepared in the BSEC Senior Officials Meetings held in January and March 2001 in order to better structure the BSEC and increase efficiency and productivity; and has been given its final form and made to be submitted for the approval of the Council of Ministers to be held in Moscow. In this document, the views agreed upon on the future path of the Organization, ranging from trade, energy, communication, transportation, agriculture, education, tourism to topics such as organized crime, arms and drug smuggling, money laundering, and corruption are included [3].

At the end of the fourth BSEC Ministerial Council meeting, which will be held in Moscow on 25-27 April 2001, Turkey will take over the rotating BSEC presidency for six months. Turkey, which has taken an important initiative in the establishment of the BSEC, has prepared a comprehensive work program under its Presidency that will accelerate the activities of the organization [1].

In the Work Program prepared by Turkey, it envisages the transformation of the organization into a project-based organization, primarily to increase the structural effectiveness of the organization; and considers that the staff of the member countries to be assigned to the organization should consists of experts, taking measures to be more efficient in the works of Secretariat [3].

Turkey, on the one hand the efficient functioning of the Secretariat shall provide the measures to be taken, on the other hand to the base workspace Organization "Economic Agenda 2000" envisages the realization of issues contained in the document [3].

a) In the field of Energy:

- Gathering of the BSEC Energy Group in Turkey with the participation of the BSEC Trade and Development Bank;

- Connecting electrical systems of BSEC countries;

- Organizing a training seminar in Turkey in the fall on energy efficiency;

- Organizing the fourth of the series conferences on energy on the Story of the Three Seas in Istanbul on June 19-22.

b) In the field of Transportation:

- Preparing a Transport Action Plan by meeting twice in Turkey with BSEC Transport Working Group [3];

- Conducting a series of studies to implement the concept of the Black Sea Ring Corridor; 
- Preparing projects for improvement of transportation infrastructure;

- Making legal arrangements to facilitate the circulation of persons and goods in the BSEC region.

c) In the field of Investment and Trade:

- Conducting studies on non-tariff barriers and border crossing practices in countries of the region;

- Preparing of Memorandum of Understanding to facilitate transportation;

- Organizing a conference with the participation of BSEC businessmen on border crossing practices;

- Establishment of Trade Development Center;

- Ensuring the exchange of knowledge and experience on SMEs;

- Organizing a seminar on the European Patent System, in which BSEC countries will also be invited;

d) In the field of Agriculture:

- Meeting of the BSEC agricultural Working Group in Turkey;

- Organizing a training program for BSEC farmers;

- Developing projects in the field of beekeeping;

- Concluding the Black Sea Convention on Live Animals and Fisheries;

- Cooperation between BSEC countries and FAO in the field of Agriculture;

e) In the field of Industry

- Organizing the BSEC meeting of Industry Ministers on SMEs, which form the backbone of the economy;

f) Cooperation Between BSEC Private Sector Organizations:

- Meeting the budget burden of the BSEC Business Council by all BSEC members;

- Organizing BSEC Business Council forums in member countries, organizing of one of these meetings in Istanbul in October 2001;

- Preparing a visa easing contract for BSEC businessmen to overcome visa difficulties;

- Preparing an Investment Charter for sustainable growth and development.

g) in the fields of Organized Crime, Drug and Arms Trafficking, Terrorism, Anticorruption and Money Laundering:

- Meeting of the BSEC Working Group on Combating Crime in Istanbul in May 2001,

- Training of BSEC country experts on drug, arms trafficking and terrorism at the OECD Istanbul Center.

- Sharing Turkey's experience with the BSEC countries so that the advisory decisions taken by the OECD Working Group on Financial Action on money laundering can also be implemented in BSEC countries.

h) Cooperation with the World Trade Organization (WTO):

- Turkey's organizing a seminar on "Regionalization" in Istanbul in June 2001 in cooperation with the WTO,

- Meeting of the BSEC Trade Working Group on facilitating trade in Istanbul with the participation of WTO experts. 

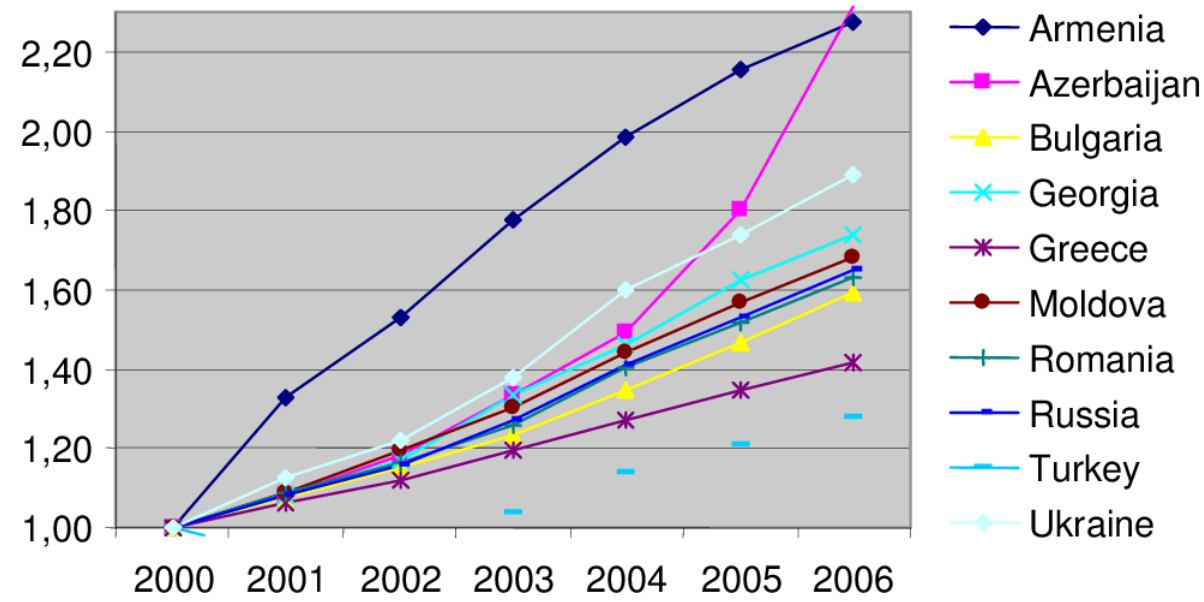

Fig. 1. Development of GDP per capita in PPP, index of $2000=1.00$ (Source: IMF World Economic Outlook, 2006).

\section{Black Sea Economic Cooperation Organization (BSEC)}

The Black Sea Economic Cooperation Organization (BSEC) was established with the initiatives of our country with a Declaration published during the Istanbul Summit on 25 June 1992. Currently, BSEC has 12 members including Albania, Azerbaijan, Bulgaria, Armenia, Georgia, Moldova, Romania, Russian Federation, Serbia, Turkey, Ukraine, and Greece [1].

The purpose of the BSEC, whose secretariat is in Istanbul; To diversify and further develop the bilateral and multilateral economic, technological and social relations between the BSEC member countries by taking advantage of their potential, geographical proximity, and the complementary features of their economies; thus, ensuring that the Black Sea basin becomes a zone of peace, stability, and welfare. The mechanism chosen to achieve this goal is economic cooperation. $t$ has come to the fore as an exemplary model for the development of political and economic relations and harmony between the member countries, maintaining stability and peace, and promoting friendship and good neighborly relations in the region [3].

Black Sea Economic Cooperation (BSEC) was established with the Declaration published during the Istanbul Summit on 25 June 1992. Its members are Albania, Azerbaijan, Bulgaria, Armenia, Georgia, Moldova, Romania, Russia, Turkey, Ukraine, Greece and Serbia and Montenegro. BSEC is a multilateral economic cooperation model based on market economy principles [2].

Turkish Ministry participates in the Culture and Tourism Working Groups meetings within the framework of the Black Sea Economic Cooperation. It is thought that Tourism Education Programs organized for the member countries of the Black Sea Economic Cooperation Organization (BSEC) and other Regional Countries and Turkic Republics, on the other hand, will enable the consolidation of friendship between countries, exchange of knowledge and experts, and development of cooperation in the field of tourism; that the events organized are important for the country image [3].

On the other hand; the BSEC Culture Working Group, which was established recently (November 1, 2006), it is aimed to introduce the culture of the region both among the member countries and other countries and to develop it by cooperating in the cultural field. 
The 1st meeting of the BSEC Culture Working Group was held in Sounion, Greece between 2 and 3 July, and the Culture Ministers Meeting was held on July 4, 2007, following this meeting. In the aforementioned Culture Working Group Meeting, the draft action plan was emphasized, the areas of cultural cooperation were discussed and the existing projects were put forward and views were exchanged on these projects [2].

Turkey undertook the BSEC Term Presidency between 1 May - 31 October 2007. On this occasion, the Tourism Working Group Meeting was held on 17-18 October 2007 in Istanbul. In the aforementioned meeting, the issues of cooperation between the public and private sector, the development of sustainable tourism in the BSEC Countries, cooperation in the field of sea tourism, and the BSEC International Tourism Permanent Secretariat planned to be established in Greece were discussed was discussed what kind of change Azerbaijan, as a part of Caspian zone, underwent for long years of Russian occupation and what this change meant for the country. Regarding that, it was also examined how the events in the world political arena would affect Azerbaijan and whether the country that had left the Soviet Union and made efforts to gain a respected place in the international arena in recent years would become successful [3].

\section{Conclusion}

The purpose of this study, which is focused on Black Sea, is to introduce the organization and to provide information about how it affects the environment, politics and sociology in the region [1].

The Black Sea Economic Cooperation Organization is a regional economic cooperation organization that has a future in Eurasia and has undertaken important tasks. On the other hand, the fact that many countries have applied to become a member of the BSEC or gain observer status shows that the Organization has started to gain ground in the international community. There is a considerable potential in the neighboring countries both financially and politically [11]. Moreover, establishing the BSEC relations with the United Nations and other international organizations and strengthening these ties will undoubtedly contribute to the establishment of closer relations of the organization with the international community $[5]$.

With the entry into force of the host country agreement in August 2000, it was enabled for the member countries to open a Permanent Representation in the presence of the BSEC and to appoint a Permanent Representative. It is believed that the activation of these Permanent Representatives will bring dynamism to the Organization [6].

In the meanwhile, Turkey is striving to implement activities during the presidency in addition to the activities mentioned above. The main goal of Turkey is to transform the Black Sea Economic Cooperation Organization into a model organization that works effectively and efficiently [3]. It is considered that the success of the BSEC will contribute to the establishment of good neighborly relations by increasing the prosperity in the countries of the region and will ensure the political and economic stability of the BSEC area between these two regions, including the Balkans and the Caucasus.

\section{References}

1. P. Manoli, The birth and evolution of the Black Sea economic cooperation, The Dynamics of Black Sea Subregionalism (Routledge Publishing, London, 2012) https://doi.org/10.4324/9781315615738-15

2. B. Turner, Black Sea economic cooperation (BSEC). The Statesman's Yearbook (2010) https://doi.org/10.1007/978-1-349-58635-6_24 
3. H. Isikal, O. Ormeci, Turkey-Black sea economic cooperation (BSEC) relations, Turkish Foreign Policy in the New Millennium (Peter Lang Publishing, London, 2010) https://doi.org/10.3726/978-3-653-05496-5/60

4. Ecological Bulletin of Research Centers of the Black Sea Economic Cooperation 15(3), (2018) https://doi.org/10.31429/vestnik-15-3

5. E. Sabanci, Organization of the Black Sea economic cooperation (Smashwords Edition, London, 2013)

6. A. Ergun, H. Isaxanli, Security and cross-border cooperation in the EU, the Black Sea region and southern Caucasus (IOS Press, London, 2013)

7. D.P. Manoli, The dynamics of Black Sea Subregionalism (Ashgate Publishing, NY, 2013)

8. F. Houston, W.D. Wood, D.M. Robinson, Black Sea security: International cooperation and counter-trafficking in the Black Sea region (IOS Press, London, 2010)

9. S.G. Luzyanin, Eastern Politics of Vladimir Putin (Vostok-Zapad Izdatelstva, Moscow, 2007)

10. The future of democracy in the Black Sea area: Hearing before the subcommittee on European affairs of the committee on foreign relations (United States CongressSenate-Committee on Foreign Relations-Subcommittee on European Affairs, 2005)

11. World Economic Outlook (International Monetary Fund, 2006) https://www.imf.org/ /media/Websites/IMF/imported-flagshipissues/external/pubs/ft/weo/2006/02/pdf/_weo0906pdf.ashx 